\title{
Die Ärzteschaft hat etwas zu sagen!
}

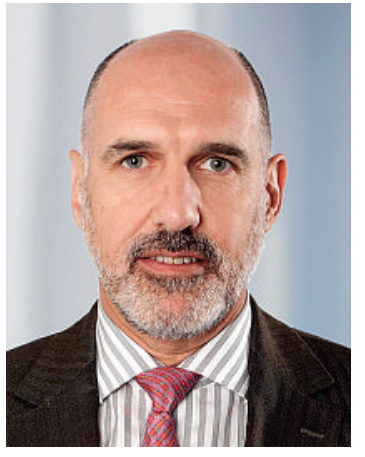

In der FMH läuft zurzeit eine Urabstimmung, und das ist weder alltäglich noch banal. Dieses Verfahren gelangte in unserer Geschichte bisher noch nicht oft zur Anwendung. Die letzten Urabstimmungen betrafen ... die $\mathrm{Ab}$ schaffung des Lateins für das Medizinstudium und - was noch eher in Erinnerung sein dürfte - die Einführung des TARMED.

Die derzeit laufende Urabstimmung betrifft den Standpunkt der FMH zu einem Referendum gegen die Vorlage zur integrierten Versorgung. Da die Ergebnisse erst in etwa zehn Tagen vorliegen, kann die verbleibende Zeit genutzt werden, um einige Überlegungen zur Bedeutung dieses Verfahrens anzustellen.

Eine Urabstimmung ist ein internes Referendum, das eine bestimmte Zahl von Mitgliedern oder Ärztegesellschaften gegen einen Beschluss der Ärztekammer ergreifen kann.

Im vorliegenden Fall geht es somit darum, den von der Ärztekammer gefassten Beschluss zu bestätigen - die FMH entscheidet über ein allfälliges Referendum gegen die Vorlage zur integrierten Versorgung, wenn deren Inhalt im Oktober definitiv feststeht - oder eine Gegenposition zu vertreten und einen sofortigen Entscheid zu fällen.

Für die FMH ist diese Urabstimmung in verschiedener Hinsicht von Bedeutung.

Zunächst zeigt es, und das ist entscheidend, dass unser demokratisches System funktioniert, was sowohl für unsere interne Dynamik als auch für unseren Zusammenhalt äusserst wichtig ist.

Die FMH ist fähig, sich Meinungsverschiedenheiten zu stellen und im Rahmen ihrer Statuten und demokratischen Prozesse Lösungen zu finden.

Die Forderung nach einer Urabstimmung ist zweifellos auch ein Zeichen dafür, dass ein Teil der FMH-Mitglieder über die Politik ihrer leitenden Organe - Ärztekammer, Delegiertenversammlung und Zentralvorstand - enttäuscht ist. Die laufende Abstimmung wird somit konkret zeigen, ob diese Organe und die Personen, die ihnen angehören, in ihrer Stossrichtung bestätigt werden oder ob sie sich neu ausrichten müssen, um die Ärztinnen und Ärzte, von denen sie gewählt wurden, weiterhin zu vertreten: Denn dazu sind wir als Verantwortliche der FMH da: die Interessen und Anliegen unserer Mitglieder zu vertreten!

Und nun? Was muss und kann diese Urabstimmung intern und nach aussen über uns zum Ausdruck bringen, abgesehen vom Resultat selbst?

In Bezug auf die interne Ebene ist einmal mehr festzustellen, dass es eine subtile Aufgabe ist, das Gleichgewicht zwischen politischer Wirksamkeit und Berücksichtigung der Stimmung der Mitglieder zu wahren: Wir müssen in der Politik «vorwärtsmachen» können, ohne übermässigen Mei- nungsschwankungen ausgesetzt zu sein, aber zugleich stets Vertreter der Mitglieder sein und bleiben.

Diese Tage zeigen, dass unsere demokratische Organisation dieses Gleichgewicht gewährleistet. Doch das System kann nur mit Respekt und gutem Willen funktionieren und mit dem Glauben an den guten Willen der anderen! Ein demokratischer Prozess soll insbesondere auch nicht der Rache oder Vergeltung dienen.

\section{Unser demokratisches System funktio- niert, und dies ist sowohl für unsere interne Dynamik als auch für unseren Zusammenhalt äusserst wichtig.}

Gegen aussen wird die Urabstimmung zeigen, dass die FMH ein solides Gebilde ist, das fähig ist, sich in Frage zu stellen, aber geeint vorzugehen - eine glaubwürdige, demokratisch legitimierte Organisation.

Und schliesslich, und dies ist heute vielleicht meine wichtigste Botschaft, möchte ich daran erinnern, dass wir Ärztinnen und Ärzte aufgrund unserer Erfahrung mit den Menschen und unserer langen humanistischen Tradition der Gesellschaft, in der wir leben, etwas zu sagen haben.

Diese Gesellschaft durchläuft bekannterweise zurzeit eine Phase der rasanten Entwicklung, in der das Gleichgewicht der Kräfte ungewiss ist - weniger der obersten politischen und militärischen Kräfte, wo dies nichts Neues ist, sondern der Kräfte auf der persönlichen und gemeinschaftlichen Ebene: Ist es der Mensch, die Gemeinschaft, oder sind es die Interessengruppen, die die Entwicklung vorgeben sollen, in die wir nolens volens einbezogen sind?

Als Ärztinnen und Ärzte setzen wir uns in unserem Berufsalltag dafür ein, in allen Patienten den Menschen zu achten. Wir müssen zeigen, dass diese Achtung auch ausserhalb unseres Sprechzimmers, unter uns, in den politischen Prozessen gilt.

Kollegen wie Bertrand Kiefer und ich haben schon oft gesagt, dass wir als Ärztinnen und Ärzte dazu aufgerufen sind, der Gesellschaft eine zentrale Botschaft zu vermitteln: Die Würde des Menschen geht den anderen Werten unter allen Umständen vor. Auch die gegenseitige Achtung in der politischen Auseinandersetzung bringt diese Botschaft an die Gesellschaft direkt zum Ausdruck - vergessen wir das in den kommenden Wochen nicht!

Dr. med. Jacques de Haller, Präsident der FMH

PS: Vor diesem Hintergrund bitte ich alle Mitglieder der FMH, ihr Stimmrecht zu nutzen! Die Einsendefrist läuft noch bis 16. September (es gilt das Datum des Poststempels). 